\title{
Gestão com responsabilidade socioambiental: o caso das empresas B
}

\author{
Mônica Tatiana Bunese Busarello ${ }^{1}$
}

\begin{abstract}
RESUMO
Repensar a economia sob o enfoque do ecodesenvolvimento é um desafio por meio das ecossocioeconomias, ou seja, uma outra economia. Entre as experiências existentes, destaca-se o movimento Empresas B que atende uma demanda de consumidores e investidores cada vez mais exigentes e conscientes quando correlacionam a questão ambiental e o impacto no consumo, sob o slogan "não ser a melhor empresa do mundo, mas a melhor para o mundo". O objetivo da pesquisa é identificar diferentes formas com as quais uma $B$-Corp pode beneficiar o meio ambiente e a comunidade local. Para isso foi utilizada uma metodologia com enfoque qualitativo e de caráter exploratório na qual se utilizou como procedimentos técnicos o levantamento bibliográfico, a pesquisa documental e a entrevista estruturada sobre a experiência do Hotel Evergreen Lodge Yosemite. As empresas B constituem um movimento pragmático de transitoriedade paradigmático entre economias que por um lado possui uma racionalidade de ganhos econômicos de curto prazo, no entanto com prejuízos socioambientais de longo prazo, e por outro lado, uma nova economia, que concilia ganhos ecossocioeconômicos, ainda em construção, no sentido que as experiências estão em curso. São exemplos de como é possível conduzir a gestão de uma empresa de forma economicamente responsável, defendendo princípios de ética social e ambiental em relação ao desenvolvimento local, entendido como comunitário, e suas imbricações com os demais espaços.
\end{abstract}

Palavras-Chave: Ecodesenvolvimento. Ecossocioeconomia. Movimento B. B-Corp.

\begin{abstract}
Rethinking the economy from the perspective of ecodevelopment is a challenge through ecosystems and economies, that is, another economy. Among the existing experiences, the Companies B movement stands out, which meets an increasingly demanding and conscious consumer and investor demand when correlating the environmental issue and the impact on consumption, under the slogan "not being the best company in the world, but the best for the world". The purpose of the research is to identify different ways in which a BCorp can benefit the environment and the local community. For this, a methodology with a qualitative and exploratory approach was used, in which the bibliographic survey, the documentary research and the structured interview about the experience of the Hotel Evergreen Lodge Yosemite were used as technical procedures. Companies B constitute a pragmatic movement of paradigmatic transience between economies that on the one hand have a rationality of short-term economic gains, however with long-term socioenvironmental losses, and on the other hand, a new economy, which reconciles ecosystem-economic gains, under construction, in the sense that the experiments are ongoing. Examples of how it is possible to conduct the management of a company in an economically responsible manner, defending principles of social and environmental ethics in relation to local development, understood as community, and its overlap with other spaces.
\end{abstract}

Keywords: Ecodevelopment. Ecosocioeconomy. B-Corp.

\section{INTRODUÇÃO}

A humanidade, por meio da economia e dos avanços tecnológicos tem criado um mundo paralelo ao natural, onde o modelo de desenvolvimento e produção compreende a natureza como fonte inesgotável de recursos (KOVALSKI, 2016).

\footnotetext{
${ }^{1}$ Turismóloga. Especialista em Gestão e Tutoria. Mestranda em Desenvolvimento Regional pela Universidade Regional de Blumenau (FURB). Email monicatbu@gmail.com
} 
O desenvolvimento é constantemente relacionado a crescimento econômico e como consequência desse padrão, temos um contraste gritante nos padrões e qualidade de vida, que segundo Celso Furtado (1959, p.10), o "desenvolvimento no mundo todo tende a criar desigualdades. É uma lei universal inerente ao processo de crescimento: a lei da concentração". Para Ignacy Sachs (2004, p.13) o "crescimento é uma condição necessária, mas de forma alguma suficiente (muito menos é um objetivo em si mesmo) para se alcançar a meta de uma vida melhor, mais feliz e mais completa para todos".

O desenvolvimento está relacionado a trocas, consumo e produção, porém é importante planejar o desenvolvimento não somente sob o viés das relações econômicas, mas também como “[...] um processo referido a condutas, hábitos e valores, individuais e coletivos condicionado pelas relações de poder em que entram os indivíduos, os grupos e as classes sociais, que se encontram num dado espaço geográfico concreto" (THEIS, 2008, p. 13).

$\mathrm{Na}$ busca por um desenvolvimento mais consciente, vários eventos aconteceram. $\mathrm{E}$ como afirma Vieira (2016), é desde os preparativos para a Conferência de Estocolmo em 1972 que a problemática ambiental, fruto da degradação intensiva, vem despertando interesse maior do poder público e da sociedade civil. A discussão ambiental passou a influenciar o desenvolvimento, onde começou a ser questionada a utilização dos recursos e seus impactos ecológicos e sociais que indicavam a necessidade de adotar novas posturas, hábitos, atitudes em relação à interação entre seres humano e meio ambiente.

Nos últimos anos têm aumentado as exigências por políticas de controle, preservação e recuperação ambiental por parte das empresas e sociedade civil organizada. Há uma constante busca por novas formas de gestão que contribuam para o sucesso dos negócios como também na construção de uma sociedade sustentável (BARRETO; MOREIRA, 2015). Nesse contexto, que surge, em 2006, o Movimento B que tem o desafio de construir uma economia mais inclusiva e sustentável (B CORPORATION, 2020c).

O objetivo da pesquisa é identificar diferentes formas com as quais uma B-Corp pode beneficiar a comunidade local e o meio ambiente. Para o desenvolvimento desta pesquisa foi selecionado uma empresa internacional com a certificação B-Corp. Os critérios de seleção foram os seguintes: (1) Empreendimento do Trade Turístico; (2) Empresa certificada, B-Corp; (3) Empresa localizada nos Estados Unidos. O empreendimento foi localizado por meio do BCorp Directory ${ }^{2}$.

\footnotetext{
${ }^{2}$ Diretório onde é possível identificar todas as empresas com certificação B Corp. Disponível em:
} $\langle$ https://bcorporation.net/directory/evergreen-lodge > 
O hotel selecionando, Evergreen Lodge Yosemite, além de ter a certificação B-Corp que significa que a empresa é comprometida social e ambientalmente, ou seja, está preocupada com os impactos que sua gestão gera no âmbito socioambiental, conta com programa de geração de trabalho e crescimento pessoal para jovens, o qual evidencia e amplia a contribuição social do empreendimento (EVERGREEN, 2018d).

Trata-se de pesquisa exploratória. Quanto à abordagem do problema é uma pesquisa qualitativa. Para alcançar e responder ao objetivo deste estudo foi utilizado os seguintes procedimentos técnicos: pesquisa bibliográfica, pesquisa documental e entrevista estruturada com o diretor do Programa de Jovens do Hotel Evergreen Lodge Yosemite, realizada, por escolha do entrevistado, por meio de endereço eletrônico em novembro de 2018. A pesquisa documental foi atualizada em abril de 2020.

\section{ECODESENVOLVIMENTO E ECOSSOCIOECONOMIAS}

O conceito de sustentabilidade embora possa parecer que é recente, principalmente se relacionar o conceito às publicações das Nações Unidas (ONU), que chamava atenção ao modelo de desenvolvimento arrolado à degradação dos recursos naturais. Porém, as raízes do termo sustentabilidade, que surgiu na Alemanha por volta de 1560, já têm mais de 400 anos e está relacionado à silvicultura (BOFF, 2012). Em uma trajetória mais recente, um fato que despertou interesse da humanidade foi a primeira foto da Terra, imagem captada por um astrônomo a partir da Lua, em 1969. A imagem chamou a atenção de muitos para o fato de que vivemos em um planeta único, cujo ecossistema é frágil e interdependente. (ONU, 2020).

A partir daí vários foram os eventos que aconteceram com o objetivo de discutir a situação do planeta com o objetivo de responder ao seguinte questionamento: como seria possível desenvolver-se sem esgotar os recursos e manter a qualidade de vida no planeta? Em meio à repercussão do Clube de Roma e às chuvas ácidas na Suécia, em 1972, a Organização das Nações Unidas (ONU) realizou em Estocolmo a Conferência das Nações Unidas sobre o Ambiente Humano, cujo principal objetivo estava pautado na construção de uma visão comum em relação à necessidade de preservação, uso consciente e melhoria do ambiente humano (NASCIMENTO, 2012).

Como consequência das abordagens científicas da época, surge o termo ecodesenvolvimento, que depois será preterido pelo termo desenvolvimento sustentável, e segundo consta, "foi o canadense Maurice Strong que usou em 1973 pela primeira vez o 
conceito de ecodesenvolvimento para caracterizar uma concepção alternativa de política do desenvolvimento" (BRUSEKE, 2003, p. 15).

O ecodesenvolvimento é um estilo de desenvolvimento que sugere que em cada ecorregião há soluções específicas para os problemas locais, considerando os dados ecológicos da mesma forma que os culturais, assim como as necessidades que são imediatas e também as de longo prazo (SACHS, 1986).

Partindo desse princípio, de analisar o todo de forma ampla e detalhada, que Sachs [1991, (1993, 2007)] elaborou as cinco dimensões do ecodesenvolvimento: (1) Dimensão Social - baseada em uma sociedade mais justa, com uma distribuição de renda mais igual; (2) Dimensão Econômica - busca por uma gestão mais eficiente dos recursos e um equilíbrio entre público e privado; (3) Dimensão Ecológica - considerando a intensificação do uso dos recursos de vários ecossistemas, a limitação do consumo de combustíveis fósseis, a redução dos resíduos e de poluição, a autolimitação do consumo material pelos países ricos, diminuindo privilégios, intensificar as pesquisas em tecnologias limpas e, por fim, a definição de regras para uma adequada proteção ambiental; (4) Dimensão Espacial - busca o equilíbrio entre o rural e urbano, bem como melhorar a distribuição de terras; (5) Dimensão Cultural - buscar raízes endógenas dos modelos de modernização, respeitando as particularidades de cada espaço. Nesse contexto o ecodesenvolvimento:

(...) estimula a reflexão e a experimentação criativa (e participativa) com modalidades de crescimento econômico que valorizem o potencial de recursos naturais e humanos em cada contexto regional específico, minimizando os custos sociais e ecológicos e promovendo a autonomia das populações envolvidas - mesmo que se faça necessário um ritmo mais lento de crescimento, o que não é forçosamente obrigatório. (VIEIRA, 1995, p.57-58)

A base normativa do ecodesenvolvimento é composta por critérios que devem ser avaliados no processo de planejamento como estratégias para o desenvolvimento. O primeiro critério normativo se refere ao processo de crescimento econômico com base em prioridades sociais visando à satisfação das necessidades básicas e a redução das desigualdades. O segundo critério, denominado prudência ecológica, tem como base um desenvolvimento pautado na harmonia entre sociedade e natureza. O terceiro critério normativo valoriza a participação e a autonomia, onde estimula uma maior participação da sociedade civil organizada na dinâmica socioeconômica e, consequentemente, no planejamento local. O quarto critério, viabilidade econômica, no sentindo de buscar novos indicadores, além dos usuais, com base em custos sociais e ambientais. Inclusive vale salientar a integração e a interdependência desses critérios dentro do contexto do ecodesenvolvimento (VIEIRA, 1995). 
Em 1987 foi elaborado o Relatório de Brundtland, que foi resultado de uma análise da Conferência de Estocolmo, a qual havia deixado algumas lacunas. Foi necessário compor uma Comissão Mundial sobre Meio Ambiente e Desenvolvimento (CMMAD), liderada pela primeira-ministra da Noruega, Gro Harlen Brundtland, por isso o nome "Relatório de Brundtland", ou como ficou mais conhecido, "Nosso Futuro Comum”, cujo propósito principal foi à elaboração de uma agenda global para mudança (NASCIMENTO, 2012). O conceito de Desenvolvimento Sustentável é resultado do "Nosso Futuro Comum" ou "Relatório de Brundtland", definido como: "aquele que atende as necessidades das gerações atuais sem comprometer a capacidade das gerações futuras de atenderem as suas necessidades e aspirações” (BOFF, 2012, p. 36). Essa definição é clássica e está presente em quase toda literatura a respeito do tema.

Segundo Paulo Freire Vieira (1995, p. 55), a Declaração de Cocoyoc foi à precursora dessa alteração de conceitos:

\begin{abstract}
A declaração de Cocoyoc em 1974, e o relatório Que Faire, apresentado no final do ano de 1975 pela Fundação Dag Hammarskjöld (por ocasião da $7^{\mathrm{a}}$ Conferencia Extraordinária das Nações Unidas), reatualizam a linha de argumentação defendida por Ignacy Sachs, mas sem que o termo ecodesenvolvimento tenha sido veiculado de forma explícita. A bibliografia faz alusão a outras denominações, como por exemplo, "um outro desenvolvimento" ou "desenvolvimento endógeno", denominações preferidas nos circuitos de comunicação das organizações internacionais atuando no campo ambiental durante esta época. Isto pode ser explicado pelo fato de que tais denominações refletiam conotações supostamente menos radicais em termos ideológicos e mais coerentes relativamente a uma diretriz de experimentação politicamente cautelosa com a ideia da nova ordem econômica internacional.
\end{abstract}

O que vai ao encontro do que Sachs (2009, p. 243) nos descreve:

(...) o colóquio de Cocoyoc marcava uma virada histórica. Uma luta efetiva contra o subdesenvolvimento demandava parar o sobre desenvolvimento dos ricos. Os países em desenvolvimento deviam se apoiar em suas próprias forças. A expressão empregada, self-reliance, não devia ser confundida com autossuficiência. Remetia à confiança em si. (...) Foi a partir daí que o "ecodesenvolvimento" se tornou uma palavra mau apreciada, desaconselhável mesmo, e progressivamente substituída em inglês pela expressão sustainable development, atrozmente traduzida em francês como développement durable.

Como muito bem observa Montibeller-Filho (1993; 2008), apesar de Ignacy Sachs concordar com as críticas ao desenvolvimento sustentável, as características em comum de ambos os conceitos são suficientes para considerá-los similares.

Muitos eventos aconteceram, assim como muitos outros ainda irão acontecer. O fato é que o tema sustentabilidade tem despertado interesse de um número cada vez maior de pessoas. A popularização do conceito de desenvolvimento sustentável, além da maior divulgação sobre a problemática ambiental, o que é positivo, trouxe também controvérsias, significados distintos 
e aplicações difusas sobre o tema, inclusive é possível observar a "luta política dos diversos segmentos sociais, muitos dos quais diretamente interessados na perpetuação do atual modelo desenvolvimentista, pela apropriação de sua significação" (MANTOVANELI JR; SAMPAIO, 2010, p. 79).

O atual modelo econômico capitalista é apontado como o principal causador de problemas socioambientais, socioespaciais e socioeconômicos, por incentivar uma má distribuição de recursos, com ganhos individuais em curto prazo sobre os coletivos de médio e longo prazo (SAMPAIO; DALLABRIDA, 2009). Repensar a economia sob o enfoque do ecodesenvolvimento é um desafio por meio das ecossocioeconomias, ou seja, uma outra economia que seja pautada em valores que visam além do lucro. O próprio termo em si ecossocioeconomia - remete-nos à complexidade oriunda da interação de três grandes áreas do conhecimento: a ecologia, o social e a economia. A ecossocioeconomia permite pensar a economia sob a perspectiva do ecodesenvolvimento, "chamada inicialmente de socioeconomia e, diante do agravamento da problemática socioambiental, redenominada por ecossocioeconomia” (SIGNORI; FELSKI; SAMPAIO, 2008, p1).

O ecodesenvolvimento foi apontado como um paradigma sistêmico, compreendendo princípios da ecologia profunda como proposta de repensar os atuais estilos de vida, da socioeconomia no sentido de ponderar as consequências sociais na ação econômica, da economia ecológica, quando esta calcula custos ambientais na ação econômica, e da ecologia humana, principalmente a premissa da inseparabilidade dos sistemas sociais e ecológicos. (SAMPAIO et al, 2012, p.156)

Não sendo necessariamente uma prática exclusiva de comunidades tradicionais, a ecossocioeconomia é também aplicável ao contexto organizacional, podendo ser denominada ecossocioeconomia das organizações, sendo que neste contexto, analisa-se a viabilidade interorganizacional, levando-se em consideração o espaço extraorganizacional e o território, além da chamada extrarracionalidade aos grupos organizados ou quase organizados no que tange os processos decisórios (SAMPAIO et al, 2012).

A ecossocioeconomia das organizações, além de repensar a economia por meio do ecodesenvolvimento, também quebra paradigmas ao opor-se ao utilitarismo economicista, buscando modelos de gestão que não apenas enfatizem ações participativas e descentralizadas, mas que também sejam, evidentemente, social e ambientalmente responsáveis (SAMPAIO; DALLABRIDA, 2009, p. 19).

Uma experiência plena em ecossocioeconomia caracteriza-se por privilegiar não apenas pessoas e organizações, mas quando seus impactos positivos atingem o território como um todo. Contudo, não apenas os efeitos das ações devem ser considerados, mas também sua força 
motriz, uma vez que mesmo que haja experiências mal sucedidas, que os aprendizados oriundos destas possam levar a novas iniciativas, mais elaboradas tanto no plano político quanto socioprodutivo (SAMPAIO, 2018).

A ecossocioeconomia, assim como o atual modelo econômico, tem limitações, porém, assume um compromisso de propor um ambiente propício a um desenvolvimento pautado na responsabilidade socioambiental. Não tem a pretensão de ser um novo modelo conceitual para indicar um novo modo de vida como propõe o ecodesenvolvimento. Pelo contrário, objetiva reorganizar estudos já existentes e sistematizá-los na prática para que possam tornar-se conhecidos (SAMPAIO, 2010). Dessa forma a ecossocioeconomia das organizações analisa e repensa a economia sob o viés do ecodesenvolvimento criando metodologias de gestão que priorizam ações participativas, descentralizadas e social e ambientalmente responsáveis (SAMPAIO; DALLABRIDA, 2009). Sendo assim, os exemplos de ecossocioeconomias não ficam limitados a economia solidária e cooperativismo, mas igualmente a exemplos de responsabilidade socioambiental, como as benefit corporation (JACOBI E BESEN, 2017 apud SAMPAIO, 2018).

\section{MOVIMENTO B COMO UMA NOVA FORMA DE GESTÃO}

Uma Benefit Corporations possui características distintas: (1) empresas com o objetivo de criar impactos positivos e significativos socioambientais; (2) proprietários e acionistas têm, além do lucro, interesses sociais e ambientais; (3) Benefit Corporations apresentam, anualmente, um relatório de seu desempenho social e ambiental. Ou seja, as Benefit Corporations são empresas que visam o lucro, porém, suas estratégias de mercado são ambientalmente e socialmente responsáveis (CLARK; BABSON, 2012).

O Movimento B ou B-Corp, que tem como objetivo principal construir uma economia mais inclusiva e sustentável, surgiu em 2006, resultado da união de três amigos que tinham como objetivo orientar empresas a um novo conceito de negócios que vai além do retorno financeiro (B CORPORATION, 2020c). Dessa forma, a criação do $B$ - $L a b$, que "é uma organização sem fins lucrativos que atende a um movimento global de pessoas que usam os negócios como uma força do bem” (B CORPORATION, 2020b), foi o ponto inicial do movimento B (RODRIGUES, 2016).

É importante observar que apesar das semelhanças existentes entre as empresas com Certificação B-Corp e as Benefit Corporations, há também algumas diferenças. As Benefit 
Corporations estão relacionadas à legislação específica para empresas com propósitos, ou seja, que tem como base um estatuto elaborado pelo Estado, para empresas que visam seu crescimento de forma sustentável, tendo como base o respeito às questões ambientais e sociais. Os Estados Unidos foram pioneiros nessa conduta de incluir em seu estatuto normas para gerir empresas de benefícios (CLARK; BABSON, 2012). Já a certificação B-Corp "foi criada para identificar, com base em critérios claros e a neutralidade de avaliação, empresas que usam o poder dos negócios para resolver problemas sociais e/ou ambientais" (COMINI, FIDELHOLC, RODRIGUES, 2014, p. 5). O quadro a seguir permite uma melhor visualização entre as diferenças citadas.

Quadro 1. Diferenças e semelhanças entre Benefit Corporation e empresas com certificação B-Corp.

\begin{tabular}{|c|c|c|}
\hline QUESTÕES & Benefit Corporations & Certificadas B-Corp \\
\hline Responsabilidade & $\begin{array}{l}\text { Diretores devem considerar o impacto em } \\
\text { todas as partes interessadas. }\end{array}$ & Idem. \\
\hline Transparência & $\begin{array}{l}\text { Deve publicar um relatório público sobre o } \\
\text { desempenho social e ambiental global } \\
\text { avaliado em relação a um padrão de } \\
\text { terceiros. }\end{array}$ & Idem \\
\hline Desempenho & Auto-relatado & $\begin{array}{l}\text { Deve atingir pontuação mínima verificada } \\
\text { na Avaliação de Impacto B }\end{array}$ \\
\hline Disponibilidade & $\begin{array}{l}\text { Disponível para empresas apenas em } 30 \\
\text { estados dos Estados Unidos. }\end{array}$ & 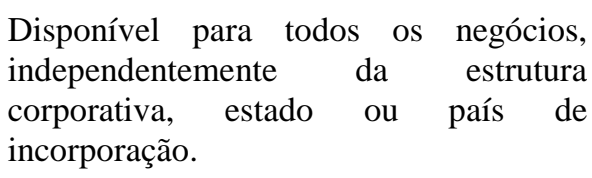 \\
\hline Custo & $\begin{array}{l}\text { Taxas de registro estaduais de USD } 70,00 \text { a } \\
\text { USD } 200,00\end{array}$ & $\begin{array}{l}\text { Taxas de certificação de USD } 500 \text { a USD } \\
50.000 / \text { ano, com base nas receitas. }\end{array}$ \\
\hline Papel do $B L a b$ & $\begin{array}{l}\text { Modelo de legislação desenvolvida } \\
\text { exclusivamente para uso das empresas de } \\
\text { benefícios; oferece ferramenta gratuita de } \\
\text { relatórios para atender aos requisitos de } \\
\text { transparência; Nenhum papel na supervisão }\end{array}$ & $\begin{array}{l}\text { Certificar e apoiar organizações, } \\
\text { oferecendo acesso ao logotipo da } \\
\text { Certified B Corporation, ao portfólio de } \\
\text { serviços e à comunidade } B \text {-Corps. }\end{array}$ \\
\hline
\end{tabular}

Fonte: BENEFIT CORP (2020).

Nesse contexto, o movimento B atua em três frentes principais:

1. Legislação na criação de um novo formato de empresas com alto padrão de propósito, prestação de contas de transparência na geração de valor compartilhado (Benefit Corporations) nos Estados Unidos; 2. Certificação de empresas para estabelecer padrões comuns para que seja possível distinguir empresas de fato 
comprometidas com a responsabilidade socioambiental, daquelas que utilizam o tema apenas como estratégia de marketing (Certificação B Corporation); 3. Investimento de Impacto, no estímulo a um mercado de capitais apropriado a este específico grupo (GRIIS). (COMINI, FIDELHOLC, RODRIGUES, 2014, p. 4)

Os investidores têm dificuldades em selecionar empresas e segmentos que sejam realmente responsáveis, o que gera uma fragilidade por parte das empresas em atraí-los, pois estes, de certa forma, também perderam a confiança em um segmento cheio de oportunidades e oportunistas. Nesse contexto, a B-Lab criou o GIIRS - Global Impact Investing Rating System, com o objetivo de gerar um relatório e classificação confiável sobre o desempenho socioambiental de empresas privadas, o qual é usado como ferramenta para o mercado de investimento de impacto (COMINI, FIDELHOLC, RODRIGUES, 2014).

Os requisitos para a certificação iniciam-se em responder o B Impact Assessment (BIA), que é uma ferramenta que avalia como a empresa se relaciona com os funcionários, clientes, comunidade e ambiente (B CORPORATION, 2020a). Essas informações servem tanto para a avaliação da certificação como para as informações para investimento de impacto (RODRIGUES, 2016). A BIA é uma ferramenta gratuita, projetada para avaliar os impactos sociais e ambientais da empresa. As áreas avaliadas, também chamadas de áreas de impacto, são as seguintes: governança, funcionários, comunidade, ambiente e clientes. A pontuação mínima é de 80 pontos e o máximo é de 200 pontos (GUIDE B CORP, 2020).

O quadro a seguir descreve cada uma destas áreas:

Quadro 2: Descrição do que o B Impact Assessment (BIA) avalia para cada área de impacto.

\begin{tabular}{|c|l|}
\hline Área de Impacto & \multicolumn{1}{c|}{ Descrição } \\
\hline \multirow{2}{*}{ Comunidade } & $\begin{array}{l}\text { Avalia as relações, a diversidade e onvolvimento de fornecedores de uma empresa } \\
\text { com a comunidade local. Ele também mede as práticas e políticas da empresa em } \\
\text { relação a serviços comunitários e doações de caridade, incluindo se o produto ou } \\
\text { serviço de uma empresa é projetado para solucionar uma questão social, como } \\
\text { acesso a serviços básicos, saúde, educação, entre outros. }\end{array}$ \\
\hline Clientes & $\begin{array}{l}\text { Mede o impacto que uma empresa tem sobre os seus clientes, concentrando-se na } \\
\text { venda de produtos ou serviços que promovem benefícios públicos, e se esses } \\
\text { produtos/serviços são direcionados para servir populações carentes. A seção } \\
\text { também mede se o produto ou serviço de uma empresa é projetado para resolver } \\
\text { uma questão social ou ambiental (melhorar a saúde, preservar o meio ambiente, } \\
\text { criar oportunidades econômicas para indivíduos ou comunidades, entre outros). ( }\end{array}$ \\
\hline Funcionários & $\begin{array}{l}\text { Avalia o relacionamento da empresa com sua força de trabalho. Ele mede como a } \\
\text { empresa trata seus trabalhadores por meio de remuneração, benefícios, treinamento } \\
\text { e oportunidades fornecidas aos trabalhadores. A categoria também se concentra no } \\
\text { ambiente geral de trabalho dentro da empresa, avaliando a comunicação entre } \\
\text { administração e trabalho, flexibilidade de trabalho, cultura corporativa e práticas de } \\
\text { saúde e segurança do trabalhador. }\end{array}$ \\
\hline
\end{tabular}




\begin{tabular}{|c|l|}
\hline Meio Ambiente & $\begin{array}{l}\text { Avalia o desempenho ambiental de uma empresa por meio de suas instalações, } \\
\text { materiais, emissões e uso de recursos e energia. As empresas respondem a perguntas } \\
\text { sobre seus canais de transporte/distribuição e o impacto ambiental de sua cadeia de } \\
\text { suprimentos. A avaliação também mede se os produtos ou serviços de uma empresa } \\
\text { são projetados para resolver uma questão ambiental, incluindo produtos que } \\
\text { auxiliam no fornecimento de energia renovável, conservam recursos, reduzem } \\
\text { desperdícios, promovem a conservação da terra/fauna silvestre, evitam substâncias } \\
\text { tóxicas/perigosas ou poluição, ou educar, medir ou consultar para resolver } \\
\text { problemas ambientais. }\end{array}$ \\
\hline Governança & $\begin{array}{l}\text { Avalia a missão geral, a ética, a responsabilidade e a transparência de uma empresa. } \\
\text { Ele mede se a empresa adotou uma missão social ou ambiental e como envolve seus } \\
\text { funcionários, membros do conselho e a comunidade para alcançar essa missão. Esta } \\
\text { seção avalia o acesso dos funcionários a informações financeiras, as oportunidades } \\
\text { dos clientes de fornecer feedback e a diversidade dos órgãos diretivos da empresa. }\end{array}$ \\
\hline
\end{tabular}

Fonte: GUIDE B CORP (2020)

Nem todas as empresas são avaliadas em todas as dimensões, pois sempre é considerado o tipo de negócio (RODRIGUES, 2016). A certificação B-Corp também exige que todas as empresas alinhem suas estruturas legais com a missão de sua empresa (GUIDE B CORP, 2020). Após responder o BIA, atingir a pontuação mínima e preencher os dados adicionais que correspondem ao perfil da empresa, o próximo passo será enviar a avaliação para a equipe da $B$-Lab. Em seguida será necessário agendar uma reunião virtual com a equipe do $B$-Lab para revisar a avaliação e apresentar determinados documentos que validam as respostas. Caso tudo esteja de acordo, finalmente é assinado o contrato e efetuado o pagamento da taxa anual. Esse processo é atualizado a cada três anos (B CORPORATION, 2020a). A transparência é outra característica importante. Depois de concluído o processo de certificação, é criado um perfil público no qual consta a pontuação da empresa e seu relatório de impacto, que ficarão disponíveis no diretório B-Corp (GUIDE B CORP, 2020).

Atualmente são mais de 2.500 empresas certificadas, situadas em 60 países (GUIDE B CORP, 2020). Na América Latina incuindo a Argentina, Brasil, Chile, Colômbia, Equador, México, Peru, Paraguai, Uruguai e America Central é o Sistema B International, criado em 2011, que supervisiona o crescimento do movimento (B CORPORATION, 2020b). O Sistema B é responsável em fazer a ligação entre as empresas da América Latina e o $B$ - $L a b$, além de adaptar os formulários de acordo com as características e particularidades de cada país (COMINI, FIDELHOLC, RODRIGUES, 2014). No Brasil são 151 empresas com certificação B (SISTEMA B, 2020).

Tornar-se uma empresa certificada B-Corp é um processo abrangente e rigoroso, que não só destaca os pontos fortes da empresa, mas também fornece um roteiro para melhorias e 
redução dos impactos. As empresas que fazem parte da comunidade $B$-Corp são empresas líderes, criando uma mudança tangível e visível nos negócios e no mundo. São empresas que redefinem o sucesso nos negócios, adotando a mudança e construindo um mundo melhor (GUIDE B CORP, 2020).

\section{O CASO DO HOTEL EVERGREEN LODGE YOSEMITE}

Inicialmente o Evergreen era um restaurante, o qual foi adaptado para dar suporte às obras da represa O'Shaughnessy, em Hetch Hetchy Valley. O local foi revitalizado depois de permanecer por 4 anos fechado. Foram construídas oito novas cabanas, totalizando então dezoito, que serviam de hospedagem. Em 2001, o Evergreem foi comprado pelos atuais proprietários, Brian Anderluh, Dan Braun e Lee Zimmerman, que desde então renovaram o local e acrescentaram 75 novas cabanas e ambientes comuns. O principal objetivo dos atuais proprietários é oferecer serviços e produtos de qualidade, ambientes privados e comunitários, além da educação ambiental por meio de experiências no Parque Nacional Yosemite (EVERGREEN, 2018a).

O Hotel está localizado em uma área rural, próximo ao Parque Nacional de Yosemite e da Floresta Nacional de Stanislau, ficando a 1,6 km da fronteira oeste de Yosemite e da entrada de Hetch Hetchy. A localização privilegiada é um diferencial do Evergreen Lodge, o que permite conhecer lugares incríveis como Yosemite Valley, Tuolumne Meadows e Hetch Hetchy Valley (EVERGREEN, 2020d).

O Evergreen Lodge Yosemite, além de uma estrutura de qualidade, se destaca por seu compromisso social e ambiental. Desde 2002, quando os atuais proprietários assumiram o hotel, implantaram o Programa de Emprego e Crescimento Pessoal para Jovens. Os principais compromissos do programa são: (1) por meio do emprego, ajudar os jovens a dar um impulso em suas vidas e descobrir seu real potencial. (2) Lugares como Yosemite devem estar acessíveis à todos, e desta forma, proporcionar novas experiências e interações com o meio ambiente (EVERGREEN, 2020b).

O programa é direcionando para jovens, de origem urbana, do norte da Califórnia, os quais trabalham no hotel desempenhando diversas funções, aprendendo assim um novo ofício (EVERGREEN, 2020b). Desde que se iniciou com o programa para jovens, o hotel empregou em média 300 jovens. O estágio é remunerado e tem duração de 4 meses (Entrevistado, 2018). São selecionados e contratados jovens entre 18 e 24 anos que não possuam a experiência 
necessária para serem admitidos em qualquer outro lugar no ramo hoteleiro, os quais também terão que trabalhar e morar no lugar. O programa tem quatro etapas: (1) oferecer um trabalho em tempo integral, com pagamento, tratamento e responsabilidades reais, como qualquer outro trabalho, mas com uma assistência extra. São várias as atividades desempenhadas pelos jovens, como limpeza, manutenção, atendimento, vendas, etc.; (2) oferecer a oportunidade de aproveitar e vivenciar uma experiência de contato direto com a natureza e expandir a sua visão quanto às possibilidades na vida; (3) oferecer suporte de serviço social individualizado e adaptado a cada jovem e assim como ajudá-los a planejar a sua carreira e educação futura; (4) oferecer a oportunidade de uma experiência saudável (EVERGREEN, 2013).

O programa é totalmente autofinanciado (Entrevistado, 2018), porém, conta com o apoio da Juma Ventures, uma organização sem fins lucrativos que incentiva a combinação entre emprego e apoio a jovens carentes. O Programa também conta com o apoio da Pacific Community Ventures, que tem como objetivo apoiar e orientar empresas que proporcionam ganhos financeiros para comunidades de baixa renda na Califórnia (EVERGREEN, 2018b).

São vários benefícios oferecidos pelo programa. Além dos previamente citados quanto à aprendizagem de um novo ofício, o que aumenta as chances de inserção no mercado de trabalho, os suportes profissional e psicológico "auxiliam os estagiários a definir e trilhar seus caminhos tanto na vida profissional, quanto pessoal" (Entrevistado, 2018). São realizadas sessões individuais com os estagiários semanalmente, a fim de assegurar que estejam no caminho certo para atingirem seus objetivos; assim como sessões em grupo, em que são abordadas habilidades importantes para a vida, como aconselhamento financeiro, gestão do tempo, habilidades de comunicação, aptidão ao trabalho, etc. Os estagiários ainda recebem orientações quanto à procura do próximo emprego, como montar um currículo e sobre entrevistas de emprego (simulações) (EVERGREEN, 2013).

Uma das regras do programa é a poupança obrigatória, que requer que os jovens economizem $50 \%$ da sua remuneração enquanto permanecerem no hotel. Ao final do estágio, além da experiência profissional que auxilia na busca por um novo emprego, a poupança auxilia em investimentos com moradia e transporte. (Entrevistado, 2018).

Porém, o real impacto na visão do diretor do programa de Jovens, entrevistado para a presente pesquisa, varia de pessoa para pessoa, onde muitos dos jovens buscam novas habilidades para ingressar no mercado de trabalho. Outros são mais atraídos pela localização e buscam viver a experiência relacionada principalmente localização do hotel, pois o Parque Nacional de Yosemite também permite que os jovens obtenham uma perspectiva diferente da 
experiência urbana. O impacto é duplo: eles aprendem a ser uma parte produtiva de uma equipe (a força de trabalho) e a desenvolver uma conscientização ambiental.

Os benefícios não abrangem apenas os jovens estagiários, pois também possibilitam uma boa relação com a comunidade e promovem a oportunidade de as pessoas se hospedarem em um local cuja missão não é só gerar lucro (Entrevistado, 2018). Há também desafios, pois a contratação de jovens sem nenhuma experiência em nenhuma área acaba exigindo mais da equipe do hotel. "Mas é este o nosso objetivo, auxiliá-los" (Entrevistado, 2018).

O jovem, ao ser selecionando para o programa passa a lidar com uma série de desafios, entre eles estar longe de casa e da família, lidar com um ambiente novo, o contraste entre vida rural e urbana, não ter acesso a celular ou internet e a gestão do tempo, pois trabalham e moram no mesmo local. Um membro da equipe mencionou que geralmente os jovens tentam fazer muito em pouco tempo, que é preciso diminuir o ritmo deles e ensiná-los a fazer uma coisa de cada vez (EVERGREENN, 2013).

Segundo o entrevistado (2018), a certificação B-Corp significa que a empresa é comprometida social e ambientalmente, ou seja, está preocupada com os impactos que sua gestão gera no âmbito socioambiental. O Programa de Emprego e Crescimento Pessoal para Jovens contribuiu de forma considerável para que a certificação fosse possível. Cabe destacar que o projeto com os jovens iniciou 5 anos antes do hotel se tornar uma $B$-Corp.

O comprometimento ambiental também é considerado no Evergreen Lodge:

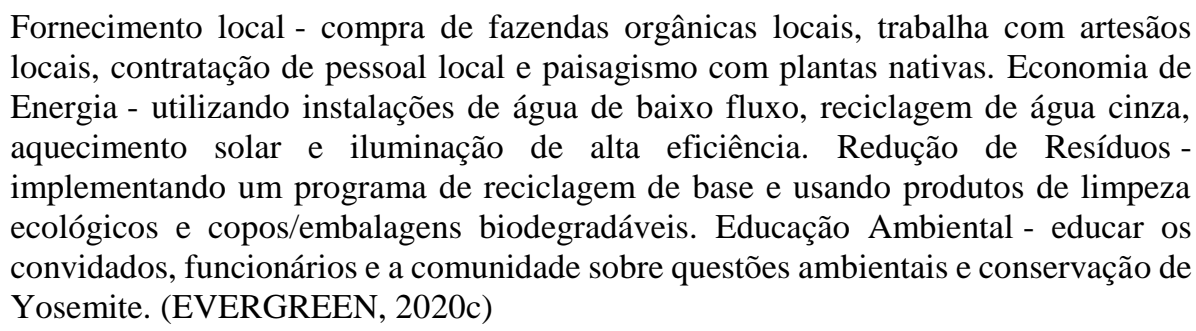

A gestão do hotel fez investimentos significativos para atingir suas metas ambientais, incluindo o desenvolvimento do primeiro sistema comercial de águas cinzas do município, que permite reutilizar mais de um milhão de litros de água de chuveiro e lavanderia todos os anos para a irrigação da paisagem (EVERGREEN, 2020c).

A certificação é resultado de uma gestão responsável. Quando questionado sobre o porquê de se tornar uma $B$-Corp, o entrevistado (2018) responde que a certificação confirma que a empresa vai além do que é exigido da maioria das empresas, o que demonstra um esforço para ser uma empresa que trabalha para com propósito. 


\title{
5. RESULTADOS E DISCUSSÕES
}

A principal característica das ecossocioeconomias, conforme citado na fundamentação teórica, é o benefício que proporciona não somente aos arranjos institucionais e socioprodutivos ao qual pertencem, mas igualmente ao território como um todo (SAMPAIO, 2018). As ecossocioeconomias, "ainda que contenham componente inovador, questionando as teorias préexistentes, podem reunir requisitos do paradigma decadente para que se realize a transitoriedade entre o velho e o novo contexto" (SAMPAIO, 2018, p. 3). Nesse sentido é possível afirmar que as empresas que integram o movimento B, a exemplo o Evergree Lodge Yosemite, permanecem em um estágio de transitoriedade entre a atual economia de mercado e a ecossocioecoomia.

\begin{abstract}
Cada vez mais conectada, a sociedade atribui conscientemente maior valor àquelas que exercerem um papel de agente de transformação social, pelos diferentes meios de que dispõem. Com transparência, as empresas passam a buscar o lucro, base de sua sustentabilidade, mas não mais como a finalidade única de sua existência. Abrindo espaço para que este seja alcançado de maneira sustentável e socialmente responsável (VASCONCELOS; MATOS; MUYLDER, 2016, p. 10).
\end{abstract}

Na tabela abaixo é possível observar a pontuação do Evergreen Lodge Yosemite como resultado do relatório emitido pelo B-Lab por meio do BIA.

Tabela 1: Pontuação no relatório de Impacto BIA para o Evergreen Lodge Yosemite

\begin{tabular}{l|l} 
Área de Impacto & Pontuação \\
\hline Governança & 13,5 \\
\hline Trabalhadores / Funcionários & 17,3 \\
\hline Comunidade & 39,3 \\
\hline Meio Ambiente & 13,2 \\
\hline Pontuação geral & 83,3
\end{tabular}

Fonte: DIRECTORY B CORPORATION (2020)

Conforme informado, a pontuação varia de 80 a 200 pontos. O Hotel Evergreen Lodge Yosemite, soma 83,3 na pontuação geral. No relatório acima é possível observar que as áreas de maior impacto são Funcionários e Comunidade. No quesito funcionários, o destaque se dá justamente pelo Programa de Emprego e Crescimento Pessoal para Jovens, que igualmente está relacionado, entre outros motivos, com o bom relacionamento com a comunidade. Pode-se considerar que 300 jovens (média informada em 2018) que estagiaram no Evergreen desde o 
início do programa em 2002 (uma média de 18 jovens por ano) foram beneficiados por meio da oportunidade de trabalho e aprendizado de novas habilidade, assim como todo acompanhamento dispensado a cada jovem citado no texto acima.

Cabe destacar que o programa é destinado aos jovens de comunidades carentes do norte da Califórnia. Foram 300 jovens que por meio da experiência vivida no programa de trabalho para jovens no Hotel Evergreen Lodge Yosemite tiveram a oportunidade de aprender sobre a importância da preservação ambiental ampliando assim suas capacidades éticas ambientais, pois são temas rotineiros no trabalho desenvolvido no hotel.

Empresas como o Hotel Evergreen Lodge Yosemite antes mesmo de ser certificada com uma B-Corp já desenvolviam práticas sustentáveis. O programa de jovens, por exemplo, foi elaborado em 2002 e a certificação aconteceu em 2007. A certificação B-Corp é consequência de uma gestão responsável, como também é uma forma de dar visibilidade e credibilidade às ações socioambientais.

Foi buscando atender uma demanda de consumidores e investidores cada vez mais exigentes e conscientes quanto ao consumo que surgiram as empresas $\mathrm{B}$, que visam não ser as melhores do mundo, mas sim para o mundo. Essas empresas, como mencionado, passam por uma rigorosa avaliação, inclusive devem rever seu estatuto, no qual deve constar que o compromisso socioambiental condiciona os resultados econômicos, além dos benefícios socioambientais proporcionados como um todo no território. As empresas certificadas fazem parte de uma rede de empresas cujo slogan é "não ser a melhor empresa do mundo, mas a melhor para o mundo". (GUIDE B CORP, 2020).

Além disso, essas empresas servem de inspiração para outras empresas, que mesmo não sendo certificadas, podem usar da ferramenta BIA, disponibilizada gratuitamente pelo B-Lab, e pode ser utilizada como parâmetro para se tornarem empresas mais conscientes e com práticas socioambientais responsáveis.

\section{CONSIDERAÇÕES FINAIS}

Empresas B fazem parte de um movimento ainda embrionário, porém, assumem um compromisso de buscar por um desenvolvimento pautado em princípios sustentáveis social e ambientalmente. São empresas que possuem uma racionalidade de ganhos econômicos de curto prazo, no entanto com prejuízos socioambientais de longo prazo, pois defendem seus princípios de ser uma empresa sustentável, e que mediante seu trabalho, contribuem com o 
desenvolvimento do local onde estão instaladas por meio do comprometimento com a comunidade e com o meio ambiente.

Entre as ações e características que diferenciam o hotel Evergreen Lodge Yosemite de outros estabelecimentos similares é possível citar seu programa para jovens, prioridade para compras de produtos locais, práticas de responsabilidade ambiental - como economia de energia, redução de resíduos e reutilização da água -, bem como a educação ambiental que proporciona por meio da experiência de interação entre comunidade, hóspedes e o Parque Nacional Yosemite.

A certificação $B$-Corp passa a assumir um importante papel na fiscalização dos impactos que os resultados das práticas citadas geram no território e que caracterizam o desenvolvimento. Essa talvez seja a principal contribuição do movimento B, certificar a veracidade dos impactos socioambientais das $B$-Corps para que os mesmos sejam consequência de uma gestão comprometida com seu propósito socioambiental.

\section{REFERÊNCIAS}

B CORPORATION. Certificação. Disponível em: https://bcorporation.net/certification. Acesso em: 28 de abril de 2020a.

B CORPORATION. Sobre o B Lab. Disponível em: https://bcorporation.net/about-b-lab. Acesso em: 28 de abril de 2020 b.

B CORPORATION. About B Corps. Disponível em: https://bcorporation.net/faqs. Acesso em: 28 de abril de 2020 c.

BENEFIT CORP. Benefit corporations and Certified B Corporations. Disponível em: https://benefitcorp.net/businesses/benefit-corporations-and-certified-bcorps?_ga=2.264749254.818640322.1588039935-1340421585.1588039935. Acesso em: 28 de abri de 2020.

BARRETO, Juliana M.; MOREIRA, Marcelo S.. Gestão Empresarial Sustentável: competência estratégica para as empresas em benefícios à sociedade. Revista de Administração e Comércio Exterior. Passo Fundo - RS, V.1, n.2, p. 40-53, 2015.

BOFF, Leonardo. Sustentabilidade: o que é - o que não é. Petrópolis: Vozes, 2012.

BRUSEKE, F. J. O problema do desenvolvimento sustentável. Desenvolvimento e natureza: estudos para uma sociedade sustentável, v. 2, p. 29-40, 2003.

CLARK JR, W. H.; BABSON, E. K. How benefit corporations are redefining the purpose of business corporations. William Mitchell Law Review, v. 38, n. 2, p. 8, 2012. 
COMINI, Graziella Maria; FIDELHOLC, Michelle; RODRIGUES, Juliana. Empresas B: princípios e desafios do movimento B Corp. Anais.. São Paulo: EAD/FEA/USP, 2014.Disponível em: http://academiab.info/bitstream/123456789/49/1/2014-SemeAdBCorp.pdf. Acesso em: 10 de dezembro de 2018.

DIRECTORY B CORPORATION. B Impact Report Evergreen Lodge. Disponível em: https://bcorporation.net/directory/evergreen-lodge Acesso em: 29 abril de 2020.

EVERGREEN LODGE. Youth Employment and Personal Growth Program. 2013. Disponível em: https://www.youtube.com/watch?time_continue=4\&v=kjZYKm18JyY. Acesso em: 29 de abril de 2020.

EVERGREEN LODGE. História e Filosofia. Disponível em: https://www.evergreenlodge.com/us/. Acesso em: 29 de abril de 2020a.

EVERGREEN LODGE. Programa Jovem. Disponível em:

https://www.evergreenlodge.com/us/youth-program/. Acesso em: 29 de abril de 2020b.

EVERGREEN LODGE. Missão Social. Disponível em: https://www.evergreenlodge.com/us/social-mission/. Acesso em: 29 de abril de 2020c.

EVERGREEN LODGE. Localização. Disponível em: https://www.evergreenlodge.com/yosemite-planning/evergreen-location/. 29 de abril de 2020d.

FURTADO, Celso. A Operação Nordeste. Rio de Janeiro: MEC; ISEB, 1959.

GUIDE B CORP. The Complete Guide to B Corp Certification for Small to MediumSized Enterprises. Disponível em:

file://C:/Users/Usuario/Downloads/Complete_Guide_to_B_Corp_Certification_for_SME.pdf. Acesso em: 28 de abril de 2020.

KOVALSKI, Rodrigo Augusto. Desenvolvimento territorial sustentável: uma análise da evolução do pensamento humano em relação à consciência sobre o meio ambiente. Revista de Humanidades, v. 31, n. 1, p. 101-120, 2016.

MANTOVANELI Jr, Oklinger; SAMPAIO, Carlos A. C.. Governança para o desenvolvimento territorial sustentável. Revista Brasileira de Ciências Ambientais, n. 18, p. 77-88, 2010.

MONTIBELLER-FILHO, Gilberto. Ecodesenvolvimento e desenvolvimento sustentável; conceitos e princípios. Textos de Economia, Florianópolis, v. 4, n. 1, p. 131-142, jan. 1993

MONTIBELLER-FILHO, Gilberto. O Mito do Desenvolvimento Sustentável: Meio ambiente e custos sociais no moderno sistema produto de mercadorias. 3 ed. Florianópolis: Ed da UFSC, 2008. 
NASCIMENTO, Elimar Pinheiro. Trajetória da sustentabilidade: do ambiental ao social, do social ao econômico. Estudos avançados, v. 26, n. 74, p. 51-64, 2012.

ONU, Organização das Nações Unidas. A ONU e o Desenvolvimento. Disponível em: https://nacoesunidas.org/acao/desenvolvimento/. Acesso em: 27 de abril de 2020.

RODRIGUES, Juliana. O movimento B Corp: significados, potencialidades e desafios. 2016. Tese de Doutorado. Universidade de São Paulo.

SACHS, Ignacy. Ecodesenvolvimento: crescer sem destruir. São Paulo: Vértice, 1986.

SACHS, Ignacy. Estratégias de transição para o século XXI: desenvolvimento e meio ambiente. São Paulo: Nobel/Fundap, 1993.

SACHS, Ignacy. Desenvolvimento e ética - para onde ir na America Latina? In

Desenvolvimento: includente, sustentável, sustentado (pp. 9-23). Rio de Janeiro: Garamond, 2004.

SACHS, Ignacy. A terceira margem: em busca do ecodesenvolvimento. Companhia das Letras, 2009.

SAMPAIO, Carlos A. C.; DALLABRIDA, Ivan S.. Ecossocioeconomia das organizações: gestão que privilegia uma outra economia. Revista da FAE, v. 12, n. 2, 2009.

SAMPAIO, Carlos A. C.. Gestão que privilegia uma outra economia: ecossocioeconomia das organizações. Blumenau: Edifurb, 2010.

SAMPAIO, Carlos A. C; FERNANDES, Valdir; ETXAGIBEL, Joseba a.; GABILONDO, Larraitz A.. Revisitando a experiência de cooperativismo de Mondragón a partir da perspectiva da ecossocioeconomia. Desenvolvimento e Meio Ambiente, v. 25, 2012.

SAMPAIO, Carlos A. C; FERNANDES, Valdir; ETXAGIBEL, Joseba a.; GABILONDO, Larraitz A.. Da socioeconomia para a ecossocioeconomia: a experiência paradigmática do cooperativismo de Mondragón. (Socio) Ecologismo dos Povos do Sul: Clamores por Justiça, número 245, p. 274-298. 2014.

SAMPAIO, Carlos A. C.. ECOSSOCIOECONOMIAS: um conceito em construção. Capítulo que integra o projeto editorial do livro Ecossocioeconomias, submetido à editora universitária da FURB, em 2018.

SIGNORI, E. L.; FELSKI, H.; SAMPAIO, C. A. C. O processo de tomada de decisão sob o viés da ecossocioeconomia das organizações: relevando a perspectiva da extraracionalidade. Revista Dynamis, v. 14, n. 2, p. 01-08, 2008.

SISTEMA B. Empresas Certificadas no Brasil. Disponível em: https://sistemab.org/empresas-b-america-latina/?fwp_presencia=brasil. Acesso em: 28 de abril de 2020. 
THEIS, Ivo. M. Desenvolvimento e Território: Questões Teóricas, Evidências Empíricas. Santa Cruz do Sul: EDUNISC, 2008.

VASCONCELOS, A. M.; MATOS, P. V.; MUYLDER, C. F. Empresas B: Responsabilidade Social Corporativa. Conference: XVIII Encontro Internacional sobre Gestão Empresarial e Meio Ambiente, 2016 - ENGEMA. Disponível em:

https://www.researchgate.net/publication/310604065_Empresas_B_Responsabilidade_social_ corporativa/citations. Acesso em: 10 de dezembro de 2018.

VIEIRA, Paulo Freire. Meio Ambiente desenvolvimento e planejamento. In: VIOLA, E. J. et al. Meio Ambiente, desenvolvimento e cidadania: desafios para as Ciências Sociais. São Paulo: Cortez, 1995.

VIEIRA, Paulo Freire. Ecodesenvolvimento: desvelando novas formas de Resistencia no Antropoceno. In: SOUZA, Cristiane M. de M. et al. Novos Talentos - Processos de educação para o ecodesenvolvimento. Blumenau: Nova Letra Editora, 2016, p.23 - 63 